\title{
Analysis on Pronunciation Assimilation and Chinese Mandarin Initial Error in Tibet Preparatory Students
}

\author{
LiaoYanhua \\ Nanchang Institute of Science \&Technology,Nanchang 330108,China
}

Keywords: Speech assimilation, Consonant errors, Chinese learning, Intensive training, Tone.

\begin{abstract}
In the native language of Tibet preparatory students, pronunciation assimilation is a very common phenomenon, and if it is brought into Chinese, it will lead to incorrect pronunciation. In order to study and analyze this pronunciation, Chinese learning students carry out the experimental tests in Tibet preparatory. This paper proposes a software testing method to obtain pronunciation error prediction analysis curves, and the reliability of the data was analyzed by using the two methods of theoretical analysis and software calculation, but it is not easy to find the phenomenon of pronunciation assimilation in Chinese. The native language and Chinese in Tibet are compared by using theoretical analysis method, the pronunciation errors of the students are predicted in Chinese learning, and then this paper has been focused on the emergence of partial error. Through the experimental data analysis, it is found that tone pronunciation are often replaced by Chinese learners with other tones, so teachers should strengthen the training and improve the accuracy of pronunciation in teaching.
\end{abstract}

\section{Introduction}

Chinese is a special voice in phonetics, its sound and shape are separate, but they have a close relationship. If the pronunciation of the Chinese language has deviation, it will have a big impact on the word, word and sentence, so the pronunciation of Chinese teaching is very important, at the same time pronunciation teaching is also difficult to Chinese teaching [1-3]. Because of the special nature of Chinese pronunciation, especially the Chinese tones are not present in many native language, so it will cause a large number of learners [4,5]. Therefore, we need to analyze the pronunciation errors between mother tongue and Chinese in Tibet preparatory students, to strengthen the training on the focus of the bias, and we can effectively improve the teaching effect of the Chinese language.

\section{Study on the Phenomenon of Speech Assimilation}

The phonetics and phonology lexicography explants as a sound segments with a word or phrase's another segmental similar any phonetic or phonological processes on the assimilation phenomenon. There are three kinds of speech assimilation, including the mutual assimilation, smooth assimilation and inverse assimilation. Sound assimilation phenomenon is that the second language learners in natural speech and usually speech bring out the phonetic phenomena from the mother tongue [6]. Learners themselves do not feel assimilation, and they are speaking naturally, rather than deliberately formed. Assimilation phenomenon is a natural habit, so it is the more labor-saving and convenient pronunciation practice.

Speech assimilation is a natural phenomenon, so it is inevitable in different languages, but speech assimilation in the native language may become the pronunciation errors in the pronunciation of the two languages. There are three kinds of factors that lead to errors in the pronunciation errors of Tibet preparatory students, the first is the negative transfer of the mother tongue, the second is the interference of the limited Chinese knowledge, and the third is that the teachers are not suitable for the analysis and practice on the phenomenon of language assimilation [7-9]. However, the main errors caused by pronunciation assimilation come from the native pronunciation habits, which is the negative transfer of the mother tongue.

In the teaching process, encountering pronunciation errors is sometimes difficult to interpret the phoneme. For example, some Tibet preparatory students are very accurate in the "Zai" Z 
pronunciation, and are not accurate in the "Zu" pronunciation; however, some preparatory students are very accurate in the "Zu" pronunciation, and are not significantly bias in the Z pronunciation [10]. Therefore, the same study of the mother tongue, some words pronunciation is accurate, and some occasions pronunciation is not accurate, so this paper carries out experimental research on the this phenomenon.

\section{The Error Analysis of Chinese Mandarin Initials in Tibet Preparatory Students}

In order to study the native language of Tibet students, the pronunciation of some words is accurate, and the phenomenon of inaccurate pronunciation is not accurate, to carry out the experimental study of the Tibet preparatory students in learning Chinese [11].

Experiment object. The experimental subjects are Chinese learning students in Tibet, in which the initial stage students are 40 , and senior stage is 20 . At the same time, each stage has 20 boys and 10 girls, in which Chinese learning time in senior stage is three years, junior stage is one years, and they are between $19-25$ years old.

Experimental procedure. The test is divided into two steps. Firstly, this paper formulas reasonable survey lists according to the actual pronunciation, and then using the recording pen carries out recording for 80 students pronunciation, at the same time recording quality must meet to be able to clear the distinguishing the sounds. Each student is familiar with speech materials in a minute, and the requirements of pronunciation should be uniform speed, natural and smooth language and clear articulation. After experiment, speech materials are repeated listening by the experimenter, to distinguish fuzzy speech with voice analysis software, so as to obtain reliable results.

Experimental analysis process. In order to illustrate the experimental and analysis process of the pronunciation errors, it is divided into six parts, and the structural framework is shown in Figure 1.

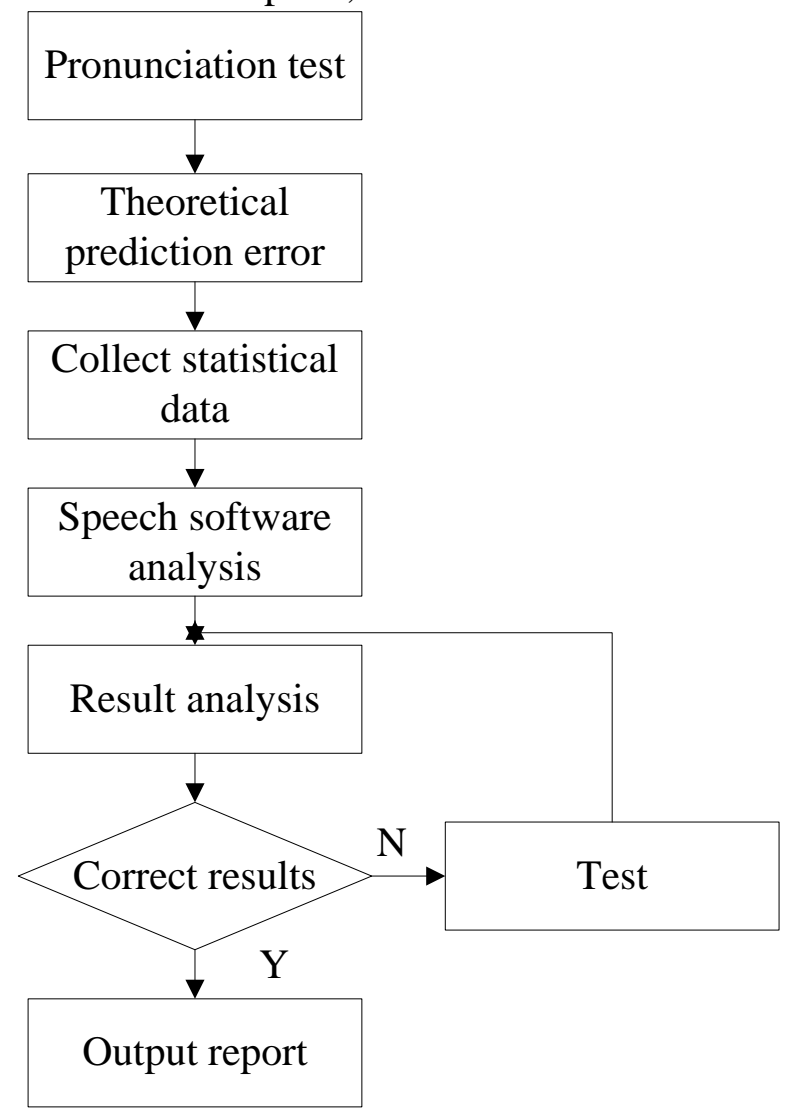

Fig. 1 The experimental analysis process of pronunciation error phenomenon

Figure 1 shows the experimental analysis process of pronunciation error phenomenon, in which it is divided into six parts, the use of theory predicting method after testing pronunciation firstly predicts the main speech errors, and then collects statistical data; the use of voice software analyzes the experimental data, to final output results; if the results are accurate, this system directly outputs 
report; if the results are not accurate, the use of software debugging method carries out analysis data, until the output of experimental results are reasonable.

\section{Experimental Result Analysis}

In the analysis of the experimental results, Tibet preppy language and Chinese are compared by the use of theoretical analysis method. The Tibet preparatory students have pronunciation errors in learning Chinese, and then combined with the experimental data analysis, so this paper obtains the focus of the errors [12]. Finally, the use of reinforcement method carries out teaching, so as to achieve good teaching results.

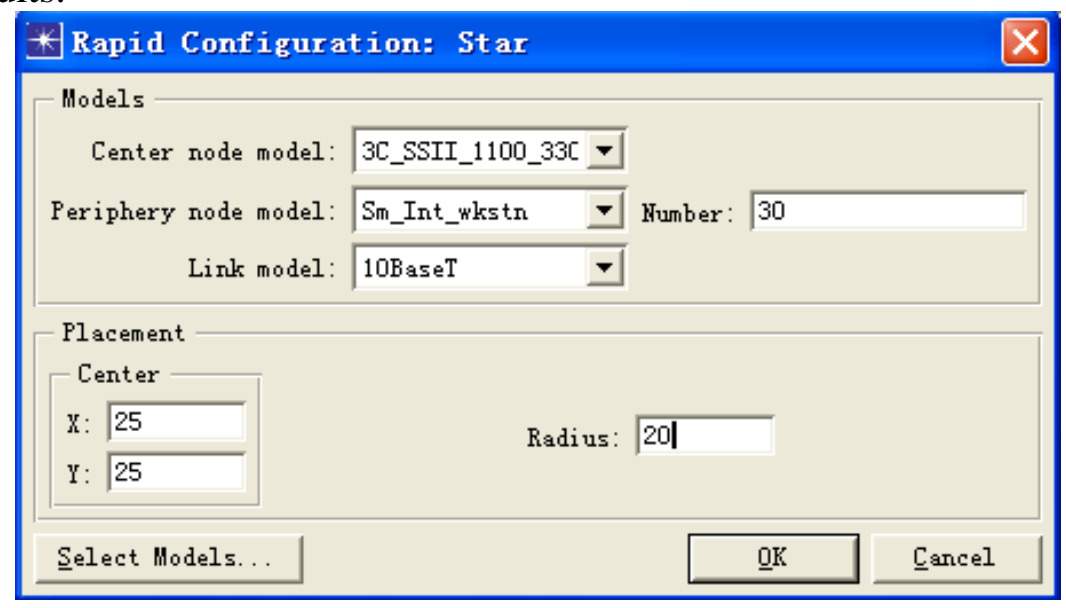

Fig. 2 Pronunciation test set table

In order to make the more reasonable experimental results, this paper analyzes pronunciation errors combined with software, and we can set up the number of pronunciation samples in the software. The number of samples is 100, 200, 300 and 400 respectively, and the test curve of the pronunciation errors as shown in Figure 3 is obtained by the analysis.

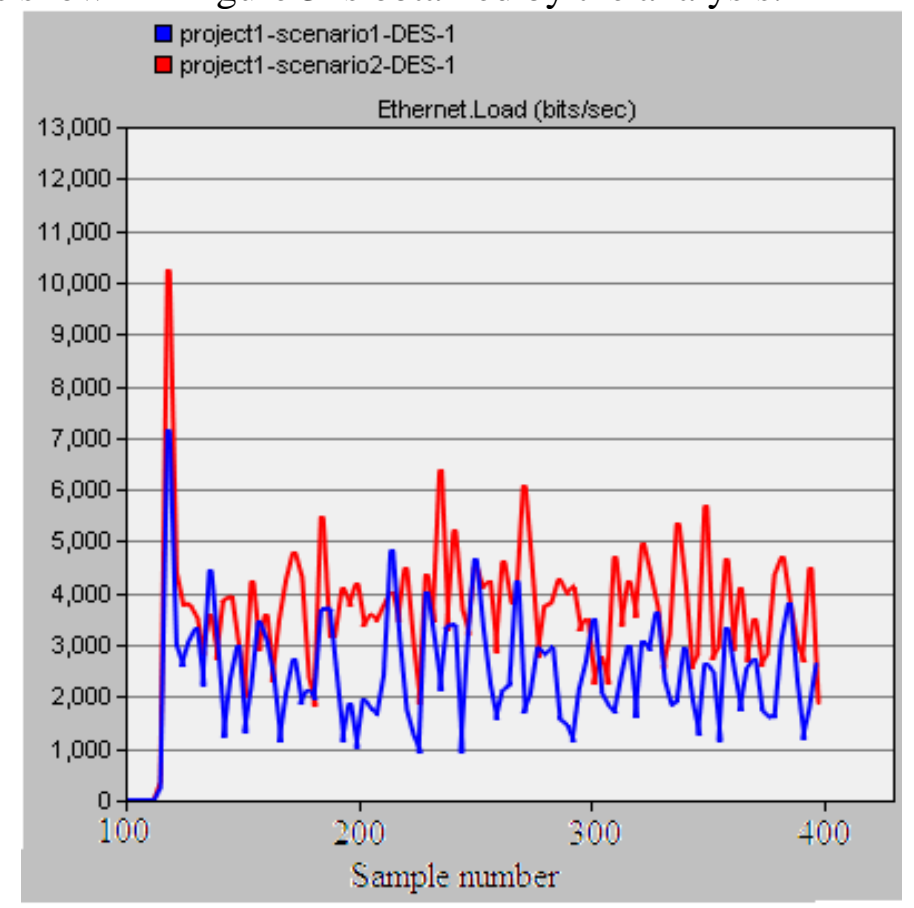

Fig.3 Pronunciation error test curve

Figure 3 shows the pronunciation error test curve, in which the focus of the analysis is that Tibet preparatory students' native language has some pronunciation in Tibet, but there is no language in the Chinese language; Tibet preparatory students' native language has not some pronunciation in Tibet, but there is language in the Chinese language, which is the focus of teaching, these need to cause the 
attention of teaching and students. From the test results, it can be seen that there are different pronunciation words in different samples; although these sounds are relatively unfamiliar to the primary Chinese learners, but they are relatively large between Tibet preparatory students' native language and Chinese language; if students pass through repeated practice, they can quickly improve the learning effect of the Chinese language.

Table 1. Pronunciation error analysis table

\begin{tabular}{|c|c|c|c|c|}
\hline \multirow{2}{*}{ Tone } & \multicolumn{4}{|c|}{ Partial error form } \\
\hline & Adjustable type & Error rate & Tone pitch & Error value \\
\hline YinPing & Reducing tone & $3.8 \%$ & 28,43 & $32.8 \%$ \\
\hline YangPing & Reducing the high profile & $2.9 \%$ & 35,362 & $33.6 \%$ \\
\hline Falling-rising tone & Rising tone & $10.8 \%$ & 218,201 & $39.9 \%$ \\
\hline Falling tone & Reducing the rise & $6.9 \%$ & 45,56 & $27.8 \%$ \\
\hline
\end{tabular}

Table 1 shows pronunciation errors analysis table obtained by experiments, in which the soft is a special tone in Chinese, and is not a separate tone. In Tibet, the native language is no such a tone, so neutral ending word in the Chinese language is the key and difficult for the Tibet students. Because of the absence of the tone, students will often read YinPing in pronunciation, even using the falling tone insteads of quietly, so teachers need this phenomenon to strengthen practice in the teaching process.

\section{Summary}

Through the analysis of the article, it is found that the phonological assimilation of the Tibet preparatory students is naturally formed in the native language; the native language is correct, but the assimilation of Chinese language tends to cause pronunciation errors. There are a large number of acceptable pronunciation assimilation in the native language, but there are pronunciation errors in the Chinese language, this paper verifies the partial error of pronunciation assimilation errors by experiments and software analysis. Through the experimental data analysis, it is found that soft pronunciation in the pronunciation errors are often replaced by Chinese learners with other tones, so teachers should strengthen the training in teaching, to improve the accuracy of pronunciation.

\section{References}

[1] X. Li. The research on the relationship among vocabulary, vocabulary depth knowledge and language ability. Foreign language teaching and research, 2014(5): 359-352.

[2] C.H. LV, B. Song, Y. Wang. The comparative study of Oral English test score standard. Foreign language teaching and research, 2013(6): 44-46.

[3] L. Zhang, Z.L. Wen, J.T. Hou. The test procedure and application of intermediate effect. Journal of psychology, 2014 (5): 620-614.

[4] X.D. Zhang. Research on the relationship between vocabulary knowledge and the two language listening comprehension. Foreign language field, 20131(2): 42-36.

[5] X.D. Zhang, Y.H. Chen. The effects of memory components on the two language listening comprehension. Modern foreign languages, 2014(3): 360-369.

[6] J.F. Wang. The application of hierarchical teaching strategies in university Chinese teaching. Chinese Education Innovation Herald, 2013(1): 66-67. 
[7] Q.S. Yu. The design and implementation of the logical regression model construction algorithm based on cloud platform. Technology Bulletin, 2013, 29(6): 137-139.

[8] Z.M. Gu, J.X. Zhang, C. Zheng. Overview of cloud computing research progress. Computer applications, 2013, 27(2): 429-433.

[9] Y. Yang. The advantages and disadvantages of multimedia teaching in English teaching. Journal of Jilin radio and TV University, 2013, 4(6): 146-147.

[10] M. Liu. The enlightenment of the modern educational technology in Singapore. Chinese audio visual education, 2013, 4 (11): 102-103.

[11] J.X. Lv. A preliminary study on the mixed learning theory in college English teaching. Journal of Changchun University of Science and Technology, 2013(7): 639-640.

[12] B. Huang, S.R. Xu, W. Pu. Design and implementation of data mining platform based on MapReduce. Computer engineering and design, 2013, 34(2): 495-501. 